\title{
Rabbit olfactory stem cells. Isolation protocol and characterization ${ }^{1}$
}

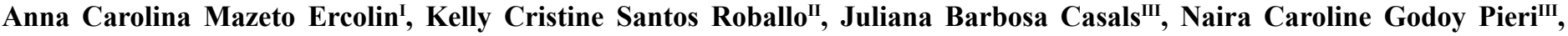 \\ Aline Fernanda Souza ${ }^{I I}$, Rodrigo da Silva Nunes Barreto ${ }^{\mathrm{IV}}$, Fabiana Fernandes Bressan' ${ }^{\mathrm{IV}}$, Matheus Levi Tajra Feitosa ${ }^{\mathrm{V}}$, Maria \\ Angélica Miglino ${ }^{\mathrm{VI}}$, Flávio Vieira Meirelles ${ }^{\mathrm{VII}}$, Carlos Eduardo Ambrósio ${ }^{\mathrm{VII}}$
}

DOI: http://dx.doi.org/10.1590/S0102-865020160010000009

IGraduated student, Veterinary Medicine Department, Faculty of Animal Sciences and Food Engineering, Universidade de Sao Paulo (USP), Pirassununga-SP, Brazil. Manuscript preparation and English language.

IIFellow PhD degree, Postgraduate Program in Animal Bioscience, Faculty of Animal Sciences and Food Engineering, USP, Pirassununga-SP, Brazil. Cell culture and manuscript writing.

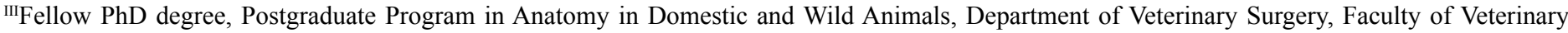
Medicine and Animal Science, USP, Sao Paulo-SP, Brazil. Cell culture and manuscript writing.

${ }^{\mathrm{IV}}$ Fellow PhD degree, Postgraduate Program in Anatomy in Domestic and Wild Animals, Department of Veterinary Surgery, Faculty of Veterinary Medicine and Animal Science, USP, Sao Paulo-SP, Brazil. Cell culture, transduction and flow cytometry.

${ }^{v}$ Fellow PhD degree, Pos doctorate National Program PNPD/CAPES, Universidade Federal do Piauí (UFPI), Teresina-PI, Brazil. Manuscript writing and English language.

${ }^{V} \mathrm{PhD}$, Chairwoman, Anatomy Unit, Department of Veterinary Surgery, Faculty of Veterinary Medicine and Animal Science, USP, Sao Paulo-SP, Brazil. Manuscript writing and English language.

${ }^{\mathrm{VII}} \mathrm{PhD}$, Associate Professor, Faculty of Animal Sciences and Food Engineering, USP, Pirassununga-SP, Brazil. Manuscript writing and English language.

\section{ABSTRACT}

PURPOSE: To describe a new technique for isolation of a mesenchymal stem cells (MSCs) population from the olfactory mucosa in rabbits.

METHODS: Olfactory stem cells (OSCs) were retrieved from under the cribriform plate of the Ethmoid bone. Several assays were accomplished to characterize the cell population and attest its viability in vitro. The cells were submitted to flow cytometry with the antibodies CD34, CD45, CD73, CD79, CD90 and CD105 and also they were induced to differentiate in three lineages. Functional evaluation involved analysis of in vitro growth behavior, colony forming unit like fibroblasts (CFU-f) and cryopreservation response. Further transduction with Green Fluorescent Protein (GFP) was also performed.

RESULTS: The OSCs showed mesenchymal features, as positive response to CD34, CD73 and CD90 antibodies and plasticity. Additionally, these cells have high proliferated rate, and they could be cultured through many passages and kept the ability to proliferate and differentiate after cryopreservation. The positive response to the transduction signalizes the possibility of cellular tracking in vivo. This is a desirable feature in case those cells are used for pre-clinical trials.

CONCLUSION: The cells harvested were mesenchymal stem cells and the technique described is therefore efficient for rabbit olfactory stem cells isolation.

Key words: Stem Cells. Olfactory Mucosa. Rabbits. 


\section{Introduction}

Stem cell therapy is a valuable tool for a wide variety of pathologies. Dominici et al. ${ }^{1}$ on their studies concluded that mesenchymal stem cells (MSCs) are an interesting source for cellular therapy due to their plasticity, immunomodulatory and self-renewing ability. An increasing clinical interest in these cells is related to the possibility of cellular transplant in situ or intravenously and immunosuppressive effects that reduce graft failure ${ }^{2,3}$ The commitment to a specific lineage is directly related to the culture conditions and environment in damaged tissue area ${ }^{4,5}$. Guerout et al. ${ }^{3}$ stated that resident cells lead MSCs to differentiate and secrete cell factors for angiogenesis or immune cell regulation.

Olfactory stem cells (OSCs) can be classified as MSCs due to the ability of adhesion into plastic culture dish, fibroblastic morphology and differentiation into various others cell lineages. Furthermore, these cells can form colonies during the first cultures ${ }^{5}$. They are able to divide in numerous times on culture and preserve growth rate, however the multipotency is dependent to the initial harvest density ${ }^{5}$. These cells can promote axonal regeneration ${ }^{6}$ and have been used in studies with intervertebral disc $^{4}$ and bone marrow injuries ${ }^{7}$.

A reliable method of tracking the transplanted MSCs in vivo is using Green Fluorescent Protein (GFP) ${ }^{8}$. Cells expressing this exogenous gene emit fluorescence (bright green light) when exposed to ultraviolet light and have been used to identify transplanted cells within the tissue and investigate their proliferation, migration and differentiation capacity 9 . This tracking property is incredible interesting and desirable for preclinical studies.

The technique described for rabbit OSCs isolation has already been reported on others animal models as: humans ${ }^{10}$, rat $^{10,11}$, and canine ${ }^{12}$. Casals et al. ${ }^{13}$ reported that rabbit is the third most common animal model, according to three different databases, and it was the animal model used on this protocol study for a better established OSCs isolation.

The present study aims to demonstrate the fore mentioned protocol represents an efficient method to rabbit olfactory stem cell characterization and isolation, as it was successfully used to characterize rodents ${ }^{10,11}$ and canine ${ }^{12}$ OSCs.

This research describes a protocol for the isolation and characterization of rabbit OSCs, as well as their expansion in vitro in order to attest that they have mesenchymal characteristics and can represent a possible source for cell therapy. The study was accomplished with rabbits since they are one of the best an animal model for human diseases, especially diseases correlated with central nervous system, as stroke $\mathrm{e}^{6,13}$.

\section{Methods}

All procedures performed on animals were approved by the Bioethics and Animal Experimentation Committee, Universidade de Sao Paulo, Faculty of Animal Science and Food Engineering (FZEA-USP).

Three-day old rabbits were used in this study after natural death had been attested (Figure 1A).

\section{Isolation and in vitro expansion}

The first step to obtain olfactory cells was the decapitation and removal of skin, as described by Girard et al. ${ }^{10}$. Then, the exposed tissue was rinsed with distilled water to eliminate blood and potential contaminants (Figure 1B). All the subsequent procedures were performed under rigorous aseptic conditions, inside a laminar hood. The olfactory epithelium was accessed after a sagittal incision of the cranium (Figure 1C). The olfactory epithelium lays in the septum, in a space delimited by the arc of the perpendicular plate, the cribriform plate and the ceiling of the nasal cavity ${ }^{10}$.

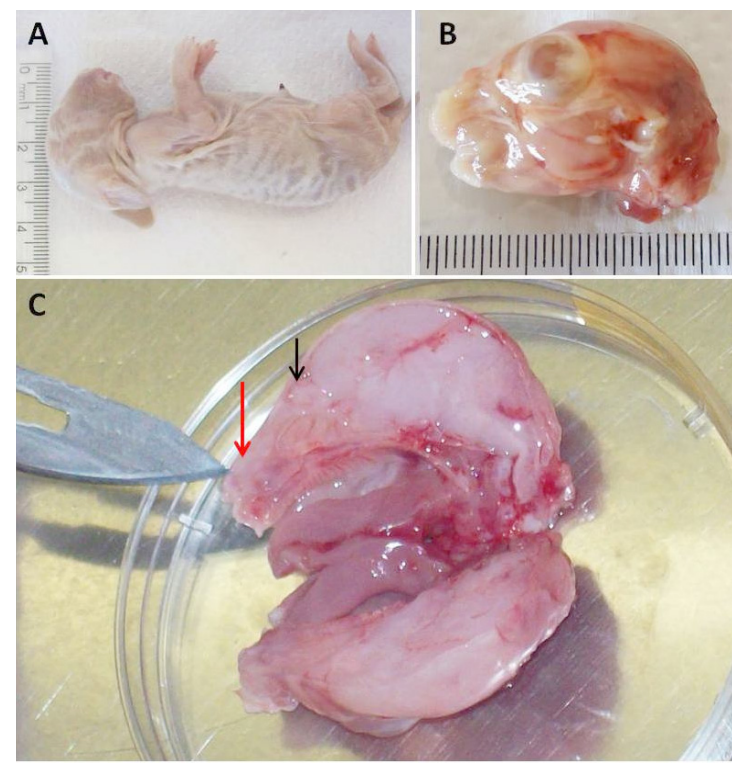

FIGURE 1 - Tissue collection procedure for olfactory stem cells sampling in rabbit. A. Three-day old rabbit used after its natural death. B. The excised head after antisepsis with distilled water to eliminate potential contaminants. C. Sagittal incision of the cranium to access the olfactory epithelium, indicated by the red arrow under the cribriform plate of Ethmoid bone. The black arrow indicates the region of the olfactory bulb. 
The epithelial fragments collected were rinsed with phosphate-buffered saline (PBS), dissociated mechanically with steril blades and submitted to enzymatic digestion with Trypsin (Triple Express - Invitrogen, Cat. N. 12604) for 15 minutes under standard conditions $\left(37^{\circ} \mathrm{C}\right.$, humidified atmosphere with $\left.5 \% \mathrm{CO}_{2}\right)$.

Cells and tissue explants were plated in $60 \mathrm{~mm}$ plastic culture dishes with Dulbecco's modified Eagle's medium F12 (DMEM F12, LGC, Cat. N. BR-30004-05) supplemented with 15\% bovine fetal serum (Hyclone, Cat. N. SH30070-03), 1\% L-glutamine (Sigma, Cat. N.G7513), 1\% Penicillin-Streptomycin (Hyclone, Cat. N. SH40003-12) and 1\% MEN Non-Essential Amino Acid solution (Invitrogen, Gibco, Cat. N. 11140).

After $72 \mathrm{~h}$ of incubation, non-adherent cells were removed and the medium was replaced every three days. Adherent cells were cultured until reaching $70 \%$ confluence and then harvested and transferred to new $60 \mathrm{~mm}$ plastic culture dish.

Rabbit olfactory stem cells were daily observed with an inverted phase contrast microscope NIKON Eclipse-TS 100. Photomicrographs were captured using the ENLTV 8.0.7 software.

\section{Functional tests}

\section{Growth curve}

Functional tests were performed to attest the cellular viability in vitro. Cells at passage 2 were monitored for 31 days to growth curve and proliferative behavior evaluation. The cells plating density was set at $1 \times 10^{4}$ and the cells were harvested during 3-4 days in DMEM F12 until 70\% confluence. Each passage was performed using trypsin and the obtained cells were replated. Cells number at each passage was quantified by counts using a hemocytometer.

\section{Cryopreservation}

Rabbit olfactory stem cells were submitted to cryopreservation in different passages. The freezing medium was constituted by DMEM F12, supplemented with 20\% fetal bovine serum, 10\% DMSO (Vetec, Cat. N. 590) and 1\% PenicillinStreptomycin.

\section{Colony forming unit like fibroblasts (CFU-f)}

The colony forming unit like fibroblasts (CFU-f) assay was adapted from a previously described protocol ${ }^{14}$. Cells obtained from rabbit olfactory epithelium were ressupended in DMEM F12 supplemented medium at a concentration of $10^{3}$ viable cells and plated on $90 \mathrm{~mm}$ plastic culture dishes prior to incubation. Microscopic analysis was performed at seven and 14 days and the medium replacement occurred every three days. When minimum 50 cells per colony were observed, cells were fixed with $4 \%$ paraformaldehyde for 30 minutes and stained with crystal violet solution (15 minutes). After rinsing the fixed cells with distilled water, it was possible to determine the number of colonies. Colonies with less than 50 cells or which morphology clearly differed from the olfactory stem cell morphology were excluded from the results.

\section{Differentiation protocols}

Cells were induced to differentiation to evaluate their plasticity. Non-induced control samples were maintained in proliferation medium during all this study.

\section{Osteogenic differentiation and Alizarin Red staining}

For Osteogenic differentiation $3.4 \times 10^{4}$ cells were resuspended in $2 \mathrm{~mL}$ StemXVivo ${ }^{\mathrm{tm}}$ Human/Mouse Osteogenic/ Adipogenic Base Media (R\&D Systems, Cat. N. CCM007) supplemented with Penicillin-Streptomycin $(1: 100)$ in a $35 \mathrm{~mm}$ plastic culture dish and incubated under standard conditions. The base medium was changed every three days until the 50$70 \%$ confluence. Medium was then replaced by $2 \mathrm{~mL}$ of the differentiation medium StemXVivo Osteogenic Supplement x20 (R\&D Systems, Cat. N. CCM008). Medium replacement was accomplished every three days and differentiation occurred after three weeks on average. Osteogenic differentiation was attested by Alizarin Red $\operatorname{stain}^{15}$. Before stain, the cells were fixed with paraformaldehyde $4 \%$ for 1 hour.

\section{Adipogenic differentiation and Oil Red staining}

For adipogenic differentiation, $1.7 \times 10^{5}$ cells were ressuspended in $2 \mathrm{~mL} \mathrm{StemXVivo}^{\mathrm{tm}}$ Human/Mouse Osteogenic/ Adipogenic Base Media supplemented with PenicillinStreptomycin $(1: 100)$ in a $35 \mathrm{~mm}$ plastic culture dish. The base medium was replaced every three days. When $100 \%$ confluence was observed, the base medium was replaced by $2 \mathrm{~mL}$ of the differentiation medium StemXVivo Adipogenic Supplement (R\&D Systems, Cat. N. CCM011). Medium was changed every three days during a period of approximately 21 days. Then, cells were fixed with $4 \%$ paraformaldehyde in PBS for $1 \mathrm{~h}$ and stained with Oil Red solution. 


\section{Neuronal differentiation and Immunofluorescence protocol}

For neuronal differentiation, $3 \times 10^{5}$ cells were plated into four-well plastic culture dish on top of a coverslip. When the cellular growth reached $70 \%$ confluence, $0.5 \mu \mathrm{L}$ of monoetilglicerol (3-mercapto-1,2 propanediol, M6145, Sigma) was added to each well. Twenty four hours after, the cells were fixed with $4 \%$ paraformaldehyde and an immunofluorescence protocol was performed for GFAP (Glial Fibrilar Acid Protein), an intracellular neuronal marker for glial cell. After medium removal, the cells were rinsed with PBS, fixed for 12 minutes with $4 \%$ paraformaldehyde and rinsed three times with DPBS (Dubbecco Phosphate Buffer Saline) to eliminate the paraformaldehyde. These procedures were followed by incubation with $1 \%$ Triton X-100 for 20 minutes and washing with $0.1 \%$ Tween diluted in DPBS. Unspecific proteins were blocked with $10 \%$ goat serum for 1 hour, followed by incubation with 1:1000 Mouse anti-GFAP primary-antibody (Pleasanton, CA, Cat. No. MOB199 - 5264) overnight at $4^{\circ} \mathrm{C}$. The negative control was incubated with PBS. After three washes with $0.1 \%$ goat serum in DPBS, it was added 1:600 Polyclonal Goat Anti-Mouse Immunoglobulins/ FITC Goat F (ab') 2 (Cat. No. F 0479) secondary antibody and remained for one hour in a dark container, at room temperature. All slides were washed three times with DPBS before mounting in Prolong containing Hoechst 33342.This protocol with adaptations was described by Walton and Wolfe ${ }^{16}$.

\section{Flow cytometry characterization}

For flow cytometry (FACSCalibur, BD) characterization, there were used $10^{5}$ cells in the first passage per tube. The cells were distributed equally in the tubes and ressuspended in $200 \mu \mathrm{L}$ of PBS. We used the following markers: CD34, CD45, CD73, CD79, CD90, CD105 and IgG as the secondary antibody. After 1 hour of incubation in a dark container to support primary antibody reaction, each tube was centrifuged at $300 \mathrm{~g}$ for three minutes and then added the secondary antibody for 30 minutes, and then each tube was centrifuged at $300 \mathrm{~g}$ for three minutes, and washed with $1 \mathrm{~mL}$ PBS. For the following analysis in the flow cytometer, the resulting pellet from each tube was ressuspended in $200 \mu \mathrm{L}$ PBS with $1 \%$ formaldehyde.

\section{Transduction with eGFP and cell sorting}

In order to evaluate the possibility of tracking the cells in in vivo studies it was performed a lentiviral transduction of the cells in culture with the exogenous gene eGFP.

Lentiviral production ${ }^{17}$ was performed by lipofection of 293FT cells (Invitrogen) according to protocol established previously. Rabbit OSCs were cultured in $60 \mathrm{~mm}$ plastic culture dishes until $30 \%$ confluence. Then, cells were transduced with 3 $\mathrm{mL}$ of viral supernatant with $6 \mu \mathrm{g} . \mathrm{mL}-1$ of hexadimethrine bromide (Polybrene, Sigma). After 24 hours, the viral solution was replaced by normal culture medium without antibiotics and incubated for $24 \mathrm{~h}$. Selection of transgenic cells was performed through antibiotic resistence by adding $8 \mu \mathrm{g} . \mathrm{mL}-1$ of blasticidin to the cultures for 10 days, and medium was changed every three days. The blasticidin concentration was previously optimized ${ }^{17}$ with a killing assay that included $0,2,4,6,8$ and $10 \mu \mathrm{g} \cdot \mathrm{mL}-1$ concentrations of blasticidin in cultures of bovine mammary epithelial cells. Cells at the fifth passage were submitted to flow cytometry analysis (FACS - fluorescent assisted cell sorting) for evaluation of transduction efficacy and sorting of GFP-positive cells. This procedure was accomplished on a FACSAria cytometer (Becton, Dickinson and Company) equipped with $488 \mathrm{~nm}$ blue laser and 530/30nm filter, using FACSDiva Version 6.1.1. software. The results were compared to non-transducted cells (control group). To purify the material, all cells in culture were recovered and data from 10.000 cells was recorded for statistical analyses.

\section{Results}

Cells in culture attached to plastic culture dishes after approximately 4-5 days of incubation. Functional evaluation of the OSCs in culture was performed through analysis of cellular growth curve, the behavior of cryopreserved cells submitted to thawing and cellular forming units like fibroblasts (CFU-f) assay.

The cellular growth curve showed an exponential growth until the seventh passage, the point of maximum population density. After that, a period of stability was followed by a decreasing growth rate at passage 15 . The cells in culture could be expanded until the passage 16, presenting substantial rate of proliferation and expansion in vitro (Figure 2).

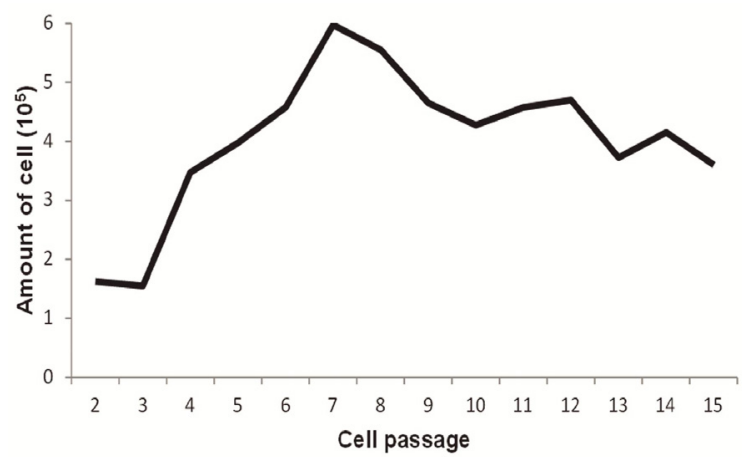

FIGURE 2 - Growth curve of mesenchymal stem cells from rabbit olfactory epithelium. Exponential growth was until the seventh passage, the point of maximum population density. After that, a period of stability was followed by a decreasing growth rate (fifteenth passage). Amount of cells represented in vertical axis $\left(10^{5}\right)$. 
The cryopreserved cells in different passages reached confluence within 3-4 day, after thawing and presented fibroblastic morphology (Figure $3 \mathrm{~A} 1$ and A2). When performing the colony forming unit like fibroblasts assay, 22 colonies were obtained per thousand of plated cells, on average (Figure 3 B1 and B2).

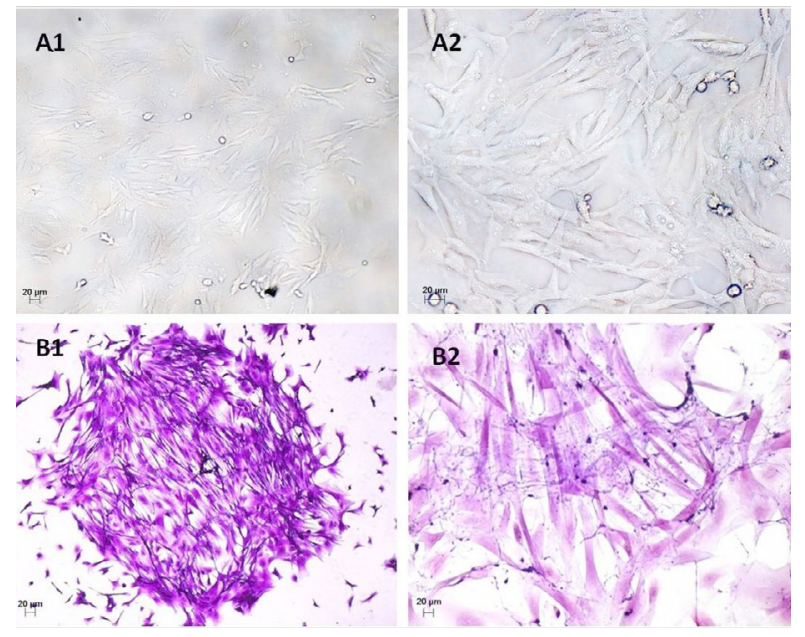

FIGURE 3 - Photomicrographs of rabbit olfactory stem cells during cellular proliferation assays. A1/A2. Evidence the spindle-like morphology. B1/B2. CFU-f stained with Crystal Violet. It can be seen a huge tendency to form colonies with fibroblasts appearance. Scale bars $=20 \mu \mathrm{m}$.

The cells studied expressed capability to commit to adipogenic (Figures $4 \mathrm{~A} 1$ and A2) and osteogenic (Figure 4 B1 and B2) cells lineages. Osteocytes-like cells showed mineralized calcium phosphate deposition that was stained by Alizarin red solution. Adipocytes could be easily discerned from the undifferentiated cells by phase contrast microscopy, adipogenic differentiation was confirmed by Oil red staining of cells with intracellular lipidic vacuoles.
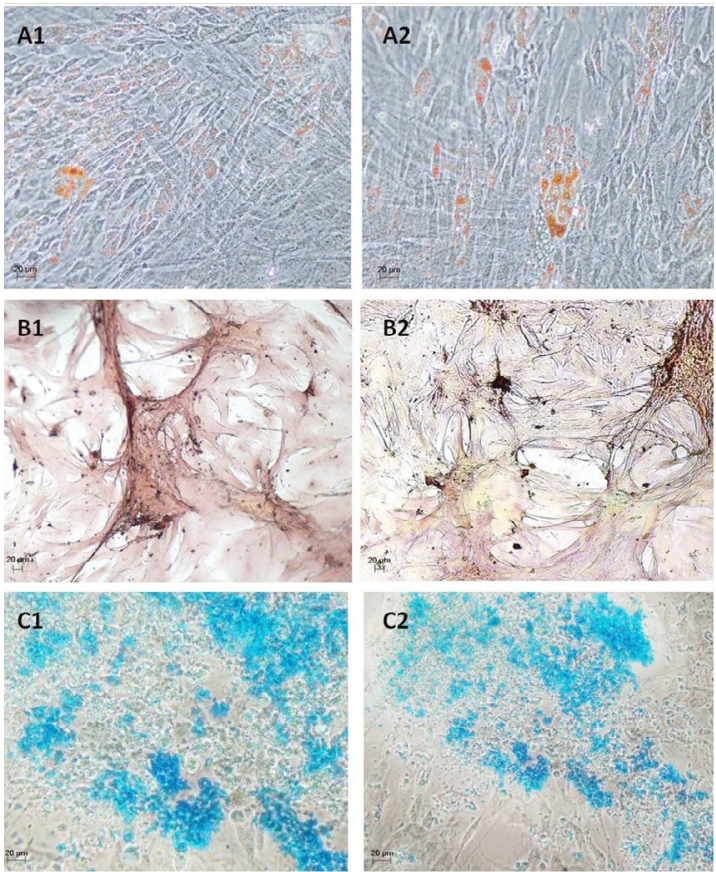

FIGURE 4 - Photomicrographs of rabbit olfactory stem cell submitted to differentiation. A1/A2. Cells were stained with Oil Red showing intracellular lipidic vacuoles, a typical feature of adipocytes. B1/B2. Cells stained with Alizarin Red showed calcium phosphate deposition in osteogenic differentiation assay. Scale bars $=20 \mu \mathrm{m}$.

Furthermore, cells in culture committed to the neuronal lineage after neuronal differentiation. It could be noticed by phenotypic characteristics as the spindle, bipolar or multipolar ${ }^{16}$ morphology (Figure $5 \mathrm{~B}$ ) and GFAP positive staining (Figure 5 $\mathrm{D}, \mathrm{E}$ and F).
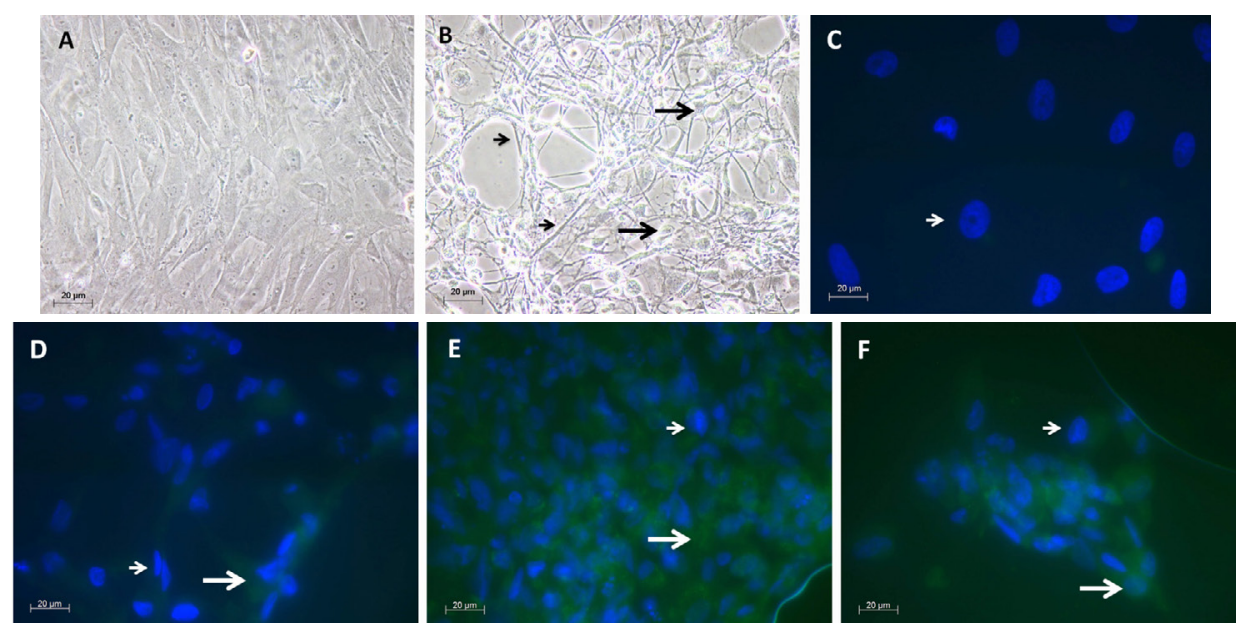

FIGURE 5 - Photomicrographs of rabbit OSCs submitted to neuronal differentiation and immunofluorescence. A. Culture of undifferentiated rabbit OSC with fibroblastic morphology. B. Rabbit OSC differentiated in neuronal cells. It is possible to analyze axonal-like cells branches (the small black arrows) and dendrite-like cells (large black arrows). C. Control with nucleus stained in blue (small white arrow) and negative staining to GFAP. D, E and F. GFAP positive staining. Small white arrows indicate nucleus and large white arrows show the cytoplasm stained in green. Scale bars $=20 \mu \mathrm{m}$. 
The investigation of surface markers by flow cytometry revealed that rabbit OSCs expressed the hematopoietic marker CD34 (10\%), but not the CD45 (0, 3\%). It was observed a very low expression of MSC-specific antigen CD105 (2.5\%), although there was positive staining to the mesenchymal markers CD73 (28\%) and CD90 (16, 7\%). However CD79 was not expressed $(0.3 \%)$ on these cells (Figure 6$)$.
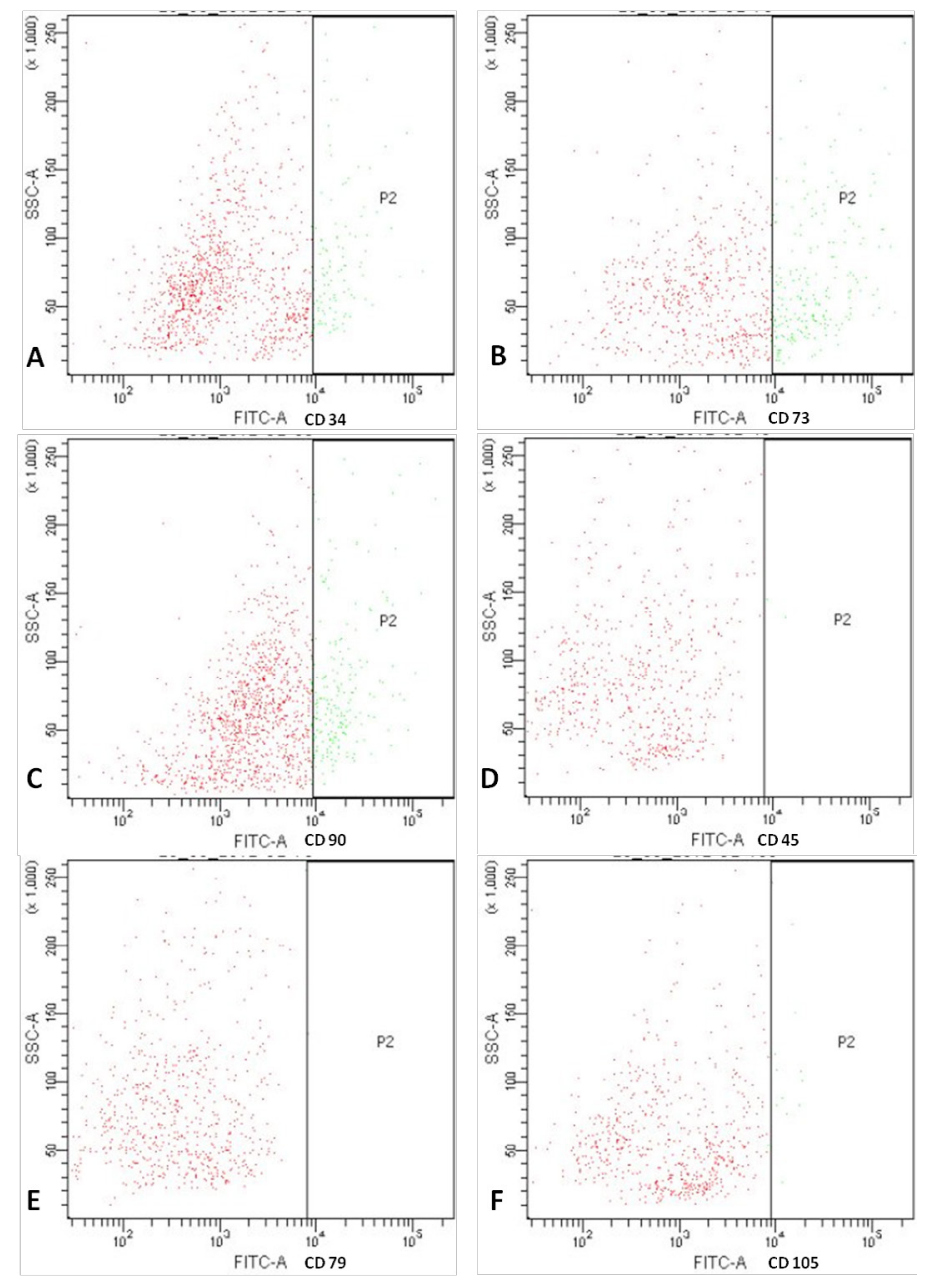

FIGURE 6 - Flow cytometry graphs for characterization of the rabbit OSCs in culture. It is possible to notice the positive expression of the cells for the antibodies CD34 (A), CD73 (B) and CD90 (C). By the contrary, there was absent expression of the antibodies CD45 (D), CD79 (E) and CD105 (F).

Flow cytometry revealed a $50 \%$ success in lentiviral transduction showed by the percentage of eGFP-positive cells (Figure 7).
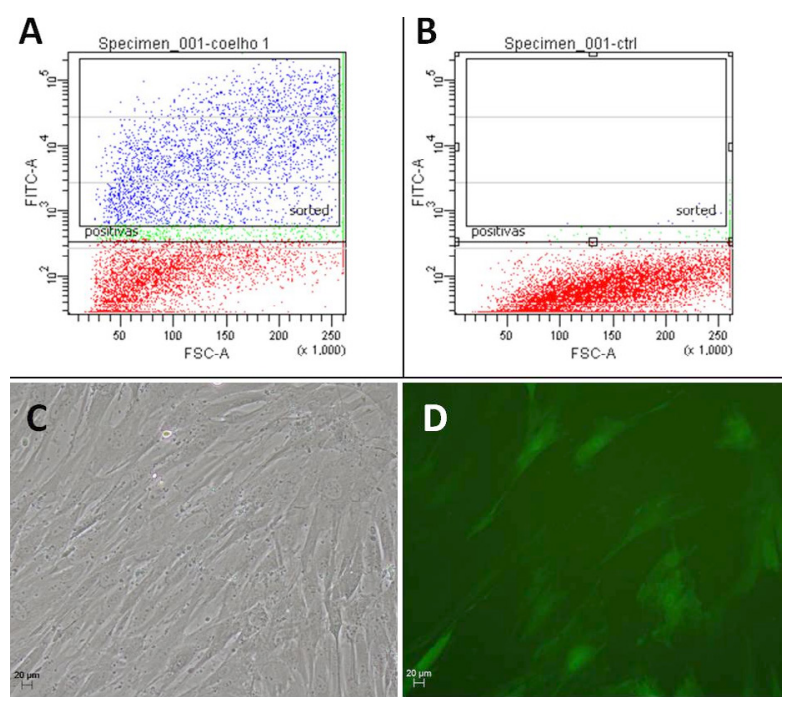

FIGURE 7 - Analysis of cellular behavior during transduction with GFP gene. The transducted cells (A) and control cells (B) submitted to flow cytometry. Rabbit olfactory stem cells in culture under bright light (C) and UV light (D). Scale bars $=20 \mu \mathrm{m}$.

\section{Discussion}

OSCs presented great viability in vitro, being expanded numerous times and cryopreserved at different passages, as suggested by Murrell et al. ${ }^{4}$.

Cellular development and growth kinetics were in accordance with the proposed by Lochhart ${ }^{18}$ for mesenchymal cells. This author established in vitro the phases of exponential, constant and decreasing growth related to the cellular physiologic activity.

Colony forming units like fibroblasts were claimed to be an important tool for determining mesenchymal cell populations. Our study, as well as the works from Dominici et al. ${ }^{1}$ and Fadel et al. ${ }^{19}$ in the study with ovine fat tissue stem cells; demonstrated OSCs originate colonies with spindle morphology as fibroblasts. The ability to adhere to plastic culture dish and be widely expanded (high proliferation potential) was observed by Zucconi et al. ${ }^{20}$ on canine MSCs from umbilical cord blood.

Cellular differentiation into three distinct lineages determines mesenchymal properties of stem cell, as declared by other group ${ }^{1}$. Our study revealed rabbit OSCs present plasticity, ability to commit with adipogenic, osteogenic and neurogenic lineages. The typical findings of each phenotype were confirmed by Zucconi et al. ${ }^{20}$ and other authors ${ }^{20-22}$. 
The cells submitted to transdifferetiation into the neuronal lineage expressed GFAP positive labeling, an antibody for Schawnn cell-like glia and the astrocyte-like glia ${ }^{21}$. Walton and Wolfe ${ }^{16}$ also demonstrated that cells from canine olfactory bulb presented positive staining to GFAP. The neuronal-like cells founded here are in consonance with others authors ${ }^{16,22}$. Corroborating with our study, Girard et al. ${ }^{10}$ showed on their studies GFAP expression on human olfactory stem cells after neuronal differentiation.

The positive staining for CD90 in flow cytometry conflicts with what was published by Lindsay, Riddell and Barnett ${ }^{23}$ for neurospheres from the lamina propria; and by Wetzig, Mackay-Sim and Murre $^{24}$ for adult olfactory stem cells isolated from rats. Kuhn and Tuan ${ }^{25}$ classified the antibodies CD73 and CD90 as MSCs markers. Our results showed that the cells in culture were positive for CD73 indicating a mesenchymal feature and in corroboration with others studies ${ }^{25}$. Vieira et al. ${ }^{26}$ found negative results when tested CD73 in canine adipose-derived stem cells. CD45 is a marker of hematopoietic stem cells ${ }^{20}$ and was not expressed in our population in culture. This result corroborate with what was attested by Kuhn and Tuan ${ }^{25}$ and Sordi ${ }^{27}$. The negative expression of CD79 was also in accordance with the results from Sordi ${ }^{27}$.

CD105 is a specific marker for $\mathrm{MSCs}^{25}$. However, we found a negative expression in our assay that is similar to the negative results related by Vieira et al. ${ }^{26}$ on canine adipose-derived stem cells.

CD34 expression in MSCs is negative, according to Sordi $^{27}$. Despite this fact, the cells in our study presented a slight but positive CD34 expression, similar to the related by Vieira et $a l .{ }^{26}$ for canine adipose-derived stem cells.

Previous researches showed that GFP-positive cells could be detected in vivo by blue LED flashlight with special filters ${ }^{28}$ Reports pointed the possibility of detecting GFP cells in internal organs of live mice using a trans-illuminated epifluorescence microscope ${ }^{8}$. This property is desirable for pre-clinical studies. Bioluminescent-based pre-clinical studies with bladder cancer showed the capability to track cancer cells in mice ${ }^{29}$. Fluorescence imaging was used to evaluate Leukemia's cells growth in mice ${ }^{30}$.

Endogenous fluorescence of OSCs transducted with GFP promotes cellular tracking in non-transducted receptors ${ }^{8}$. This enables marked rabbit olfactory stem cells to be a potential source for pre clinical studies with neurodegenerative diseases for example ${ }^{6,7}$.

The characterization assays described in this research proved the cells cultured were MSCs, confirming that the isolation protocol was efficient to isolate rabbit olfactory stem cells. This efficacy was reported for canine ${ }^{12}$ and rodents ${ }^{10,11}$ olfactory stem cells isolated using protocols very similar to the one used in the present study.

\section{Conclusions}

Rabbit olfactory stem cells showed great proliferation rate in vitro, confirming the isolation protocol and culture conditions were efficient and favorable for their development until high passages. The capacity of adhesion to plastic, commitment into different lineages and CFU-f ability, and also CD73 and CD90 expression, proved the stem cells in culture were MSCs. Additionally, the cellular growth curve and positive response to thawing reinforce their viability in vitro. The successful transduction and positive GFP expression offer the possibility of cellular tracking in case of in vivo studies. Rabbit olfactory stem cells represent an interesting source to neurodegenerative diseases research for their possibility of neuronal differentiation.

\section{References}

1. Dominici M, Le Blanc K, Mueller I, Slaper-Cortenbach I, Marini F, Krause D, Deans R, Keating A, Prockop D, Horwitz E. Minimal criteria for defining multipotent mesenchymal stromal cells. Cytotherapy. 2006;8(4):315-7. PMID: 16923606.

2. Ball LM, Bernardo ME, Roelofs H, Lankester A, Cometa A, Egeler RM, Locatello F, Fibbe WE. Cotransplantation of ex vivo expanded mesenchymal stem cells accelerates lymphocyte recovery and may reduce the risk of graft failure in haploidentical hematopoietic stem-cell transplantation. Blood. 2007 Oct 1;110(7):2764-7. PMID: 17638847.

3. Guerout N, Derambure C, Drouot L, Bon-Mardion N, Duclos C, Boyer O, Marie JP. Comparative gene expression profiling of olfactory ensheathing cells from olfactory bulb and olfactory mucosa. Glia. 2010 Oct;58(13):1570-80. PMID: 20549746.

4. Murrell W, Sanford E, Anderberg L, Cavanagh B, Mackay-Sim A. Olfactory stem cells can be induced to express chondrogenic phenotype in a rat intervertebral disc injury model. Spine J. 2009 Jul;9(7):585-94. PMID: 19345615.

5. Sotiropoulou PA, Perez SA, Salagianni M, Baxevanis CN, Papamichail M. Characterization of the optimal culture conditions for clinical scale production of human mesenchymal stem cells. Stem Cells. 2006 Feb;24(2):462-71. PMID: 16109759.

6. Krudewig C, Deschl U, Wewetzer K. Purification and in vitro characterization of adult canine olfactory ensheathing cells. Cell Tissue Res. 2006 Dec;326(3):687-96. PMID: 16788833.

7. Marshall CT, Lu C, Winstead W, Zhang X, Xiao M, Harding G, Klueber KM, Roisen FJ. The therapeutic potential of human olfactory-derived stem cells. Histol Histopathol. 2006 Jun;21(6):63343. PMID: 16528674.

8. Yang M, Baranov E, Jiang P, Sun FX, Li XM, Li L, Hasegawa S, Bouvet M, Al-Tuwaijri M, Chishima T, Shimada H, Moossa AR, Penman S, Hoffman RM. Whole-body optical imaging of green fluorescent protein-expressing tumors and metastases. Proc Natl Acad Sci U S A. 2000 Feb 1;97(3):1206-11. PMID: 10655509.

9. Sirerol-Piquer MS, Cebrian-Silla A, Alfaro-Cervello C, Gomez- 
Pinedo U, Soriano-Navarro M, Verdugo JM. GFP immunogold staining, from light to electron microscopy, in mammalian cells. Micron. 2012 Apr;43(5):589-99. PMID: 22227011.

10. Girard SD, Deveze A, Nivet E, Gepner B, Roman FS, Feron F. Isolating nasal olfactory stem cells from rodents or humans. J Vis Exp. 2011 Aug;22(54):2762-6. PMID: 21876529.

11. Rodrigues MN. Avaliação do transplante de células-tronco do epitélio olfatório de ratos em coelhos da raça Nova Zelândia submetidos a trauma medular (Mestrado). Universidade de São Paulo, Faculdade de Medicina Veterinária e Zootecnia, Departamento de Cirurgia: São Paulo; 2011.

12. Alves FR, Guerra RR, Fioretto ET, Delgado JC, Machado Junior AAN, Ambrosio CE, Kerkis I, Miglino MA. Establishment of a protocol for obtention of neuronal stem cells lineages from the dog olfactory epithelium. Pesq. Vet. Bras. 2010;30(4):363-72. doi: 10.1590/S0100-736X2010000400014.

13. Casals JB, Pieri NC, Feitosa ML, Ercolin AC, Roballo KC, Barreto RS, Bressan F F, Martins DS, Miglino MA, Ambrosio CE. The use of animal models for stroke research: a review. Comp Med. 2011 Aug;61(4):305-13. PMID: 22330245.

14. Wenceslau CV, Miglino MA, Martins DS, Ambrosio CE, Lizier NF, Pignatari GC, Kerkis I. Mesenchymal progenitor cells from canine fetal tissues: yolk sac, liver, and bone marrow. Tissue Eng Part A. 2011 Sep;17(17-18):2165-76. PMID: 21529262.

15. Sottile V, Thomson A, McWhir J. In vitro osteogenic differentiation of human ES cells. Cloning Stem Cells. 2003;5(2):149-55. PMID: 12930627.

16. Walton RM, Wolfe JH. In vitro growth and differentiation of canine olfactory bulb-derived neural progenitor cells under variable culture conditions. J Neurosci Methods. 2008 Mar 30;169(1):158-67. PMID: 18261803.

17. Monzani PS, Bressan FF, Mesquita LG, Sangalli JR, Meirelles FV. Beta-casein gene expression by in vitro cultured bovine mammary epithelial cells derived from developing mammary glands. Genet Mol Res. 2011 Apr 12;10(2):604-14. PMID: 21491370.

18. Lockhart JA. An interpretation of cell growth curves. Plant Physiol. 1971 Sep;48(3):245-8. PMID: 16657773.

19. Fadel L, Viana BR, Feitosa MLT, Ercolin ACM, Roballo KCS, Casals JB, Pieri NC, Meirelles FV, Martins DS, Miglino MA, Ambrosio CE. Protocols for obtainment and isolation of two mesenchymal stem cell sources in sheep. Acta Cir Bras. 2011 Aug;26(4):267-73. PMID: 21808838.

20. Zucconi E, Vieira NM, Bueno DF, Secco M, Jazedje T, Ambrosio CE, Passos-Bueno MR, Miglino MA, Zatz M. Mesenchymal stem cells derived from canine umbilical cord vein--a novel source for cell therapy studies. Stem Cells Dev. 2010 Mar;19(3):395-402. PMID: 19290805.

21. Pixley S K. The olfactory nerve contains two populations of glia, identified both in vivo and in vitro. Glia. 1992;5(4):269-84.PMID: 1534071

22. Grzesiak J1, Marycz K2, Szarek D3, Bednarz P4, Laska J5. Polyurethane/polylactide-based biomaterials combined with rat olfactory bulb-derived glial cells and adipose-derived mesenchymal stromal cells for neural regenerative medicine applications. Mater Sci Eng C Mater Biol Appl. 2015 Jul;52:163-70. PMID: 25953554.

23. Lindsay SL, Riddell JS, Barnett SC. Olfactory mucosa for transplantmediated repair: a complex tissue for a complex injury? Glia. 2010 Jan 15;58(2):125-34. PMID: 19606497.

24. Wetzig A, Mackay-Sim A, Murrell W. Characterization of olfactory stem cells. Cell Transplant. 2011;20(11-12):1673-91. PMID 21535908
25. Kuhn NZ, Tuan RS. Regulation of stemness and stem cell niche of mesenchymal stem cells: implications in tumorigenesis and metastasis. J Cell Physiol. 2010 Feb;222(2):268-77. PMID: 19847802.

26. Vieira NM, Brandalise V, Zucconi E, Secco M, Strauss BE, Zatz $M$. Isolation, characterization, and differentiation potential of canine adipose-derived stem cells. Cell Transplant. 2010;19(3):279-89. PMID: 19995482.

27. Sordi V. Mesenchymal stem cell homing capacity. Transplantation. 2009 May 15;87(9 Suppl):S42-5. PMID: 19424004.

28. Hoffman RM. Use of GFP in in vivo imaging: concepts and misconceptions. Proc SPIE. 2008;68680E (6868):7. doi: 10.1117/12.774181.

29. van der Horst G, van Asten JJ, Figdor A, van den Hoogen C, Cheung H, Bevers, RFR, Pelger RC, van der Pluijm G. Real-time cancer cell tracking by bioluminescence in a preclinical model of human bladder cancer growth and metastasis. Eur Urol. 2011 Aug;60(2):337-43. doi: 10.1016/j.eururo.2011.05.005.

30. Terziyska N1, Castro Alves C, Groiss V, Schneider K, Farkasova K, Ogris M, Wagner E, Ehrhardt H, Brentjens RJ, zur Stadt U, Horstmann M, Quintanilla-Martinez L, Jeremias I. In vivo imaging enables high resolution preclinical trials on patients' leukemia cells growing in mice. PLoS One. 2012;7(12):e52798. doi: 10.1371/ journal.pone.0052798.

\section{Acknowledgements}

To Dr. Paulo Sérgio Manzoni for lentiviral transfection and assistance with the transduction assays, and Jamey Jay Cooper for English revision.

\section{Correspondence:}

Dr. Carlos Eduardo AmbrosioFaculdade de Zootecnia e Engenharia de Alimentos - USP

Avenida Duque de Caxias Norte, 225 Campus13635-900 Pirassununga - SP Brasil

Tel.: (55 19)3565-4112

ceambrosio@usp.br

cajuvet@uol.com.br

Received: Sept 23, 2015

Review: Nov 19, 2015

Accepted: Dec 20, 2015

Conflict of interest: none

Financial sources: $\mathrm{CNPq}$ and RUSP

${ }^{1}$ Research performed at Laboratory of Morphophysiology and Molecular Development, Department of Veterinary Medicine, Faculty of Animal Sciences and Food Engineering, Universidade de São Paulo (FZEAUSP), Pirassununga-SP, Brazil. 